\title{
Violencia de género, políticas públicas para su enfrentamiento y el papel del Trabajo Social en Brasil
}

\author{
Trabajo de Reflexión y Planteamientos Metodológicos \\ Teresa Kleba Lisboa ${ }^{14}$
}

\section{Introducción}

En Brasil y en la mayoría de los países de América Latina, 95\% de los profesionales de Trabajo Social son mujeres, quienes en el cotidiano de su intervención atienden mayoritariamente a personas del sexo femenino. Estas profesionales, confrontan una creciente demanda de situaciones atravesadas por cuestiones de género e imbricadas con cuestiones de clase, raza/etnia, que caracterizan exclusión, discriminación, explotación, opresión, desigualdad social, relaciones de poder y de violencia, entre otras. Tales situaciones asumen materialidad a través de problemáticas como la violencia doméstica; la violencia sexual contra mujeres y niñas/os; las violencias de género (lesbofobia, homofobia, transfobia); el embarazo no deseado y la penalización del aborto; el abandono y la violencia contra mujeres ancianas; la discriminación de las mujeres en el mundo del trabajo; las condiciones precarias en que viven las mujeres presas; la discriminación en función de la raza o de la etnia, o la orientación sexual; las luchas por la adopción que llevan a cabo parejas homoafectivas; entre otras.

Desde el lugar de Trabajadora Social y profesora de la materia "Trabajo Social y relaciones de género", se propone en este

${ }^{14}$ Doctora en Sociología, Pos Doctorado en el Programa de Estudios de Género (PUEG) de la Universidad Nacional Autónoma de México UNAM, México. Profesora da Universidad Federal de Santa Catarina, Florianópolis, Brasil. Correo electrónico: tkleba@gmail.com 
Artículo ${ }^{15}$ discutir la complejidad que envuelve el concepto "violencia de género" remitiendo a las cuestiones que abarcan el enfrentamiento de la violencia contra la mujer y llamando la atención para el papel del Estado, el cual debe garantizar las políticas públicas. Se resalta, en este sentido, el papel de las (los) Trabajadoras Sociales como fundamental junto a esa cuestión, a la vez que se sugiere que los cursos de Trabajo Social incorporen en sus programas contenidos que preparen a los profesionales para trabajar con situaciones de violencia, y se promueve un trabajo interdisciplinar en la atención a las personas que procuran estos servicios.

\section{E1 Trabajo Social y la cuestión de la violencia de género}

En el panorama de las nuevas interfaces que se presentan para la profesión, la violencia de género se ha constituido gradualmente como campo de intervención del Trabajo Social. En los últimos años, las luchas libradas por los Movimientos Feministas alcanzaron conquistas en relación a los derechos de las mujeres y pasaron a visibilizar la cuestión de la violencia, sacándola del espacio privado para transformarla en política pública.

En este escenario de avances, en Brasil, las Trabajadoras Sociales han sido llamadas/os a trabajar con situaciones de violencia en Instituciones como: Centros de Referencia en Atendimiento a las Mujeres en Situación de Violencia - (CREMVs); Juzgados de Violencia Doméstica y Familiar contra la Mujer; en los Centros de Referencia Especializados en Asistencia Social (CREAS); junto a los Protocolos de Violencia, en Hospitales, Maternidades, Puestos de Salud, Estaciones de Policía; integrando el equipo interdisciplinar en el Atendimiento Socio Jurídico junto a las Prácticas Forenses de los estudiantes de Derecho en las Universidades; junto a los Consejos Tutelares y Consejos de los Derechos de las Mujeres, entre otros.

La complejidad que envuelve el concepto "violencia de género" señala que, más allá de la fuerza física existen otros tipos de violencia que se ejercen por imposición social o por presión psicológica: la violencia emocional, invisible, simbólica, económica, entre otras, cuyos efectos producen tanto o más daño que la acción física. De acuerdo con la Organización de las $\mathrm{Na}$ -

${ }^{15}$ Una versión de este artículo fue publicada en la Revista Temporalis, Brasília (DF), año 14, n. 27, p. 33-56, ene./jun. 2014. 
ciones Unidas (como se citó en Velázquez, 2006), la Violencia de Género es todo acto de violencia que tenga o pueda tener como consecuencia un daño o sufrimiento físico, sexual o psicológico para la mujer. Esta definición incluye también las amenazas de tales actos, la coacción y la privación arbitraria de la libertad, tanto en el caso en que las mismas hayan sido producidas en la vida pública o en el espacio privado.

La violencia de género engloba varias formas de violencia: violencia doméstica, violencia contra la mujer, violencia familiar o intrafamiliar, violencia conyugal, violencia sexual (en el interior de la familia y en diferentes ámbitos de la comunidad), violencia psicológica, patrimonial, trata de mujeres y niñas para fines de prostitución, entre otras. Las temáticas más específicas como el abuso sexual de niñas/os y adolescentes, maltrato infantil, incesto (violencias ejercidas además por el hecho de ser mujeres) también están incluidas en este vasto concepto en el que cabe una diversidad de tipologías. Parafraseando a Velázquez (2006), la violencia de género nos conduce a abordarla desde la perspectiva individual hasta lo colectivo. Nos conduce también, a repensar los límites de la ética y de los derechos humanos.

A pesar de que las evidencias apunten datos que se tornan públicos a través de registros, las violencias cotidianas que ocurren entre "cuatro paredes", en el interior de las familias, en los espacios de trabajo, de estudio, en los consultorios y en las calles tienden a ser silenciadas o invisibilizadas. Gran parte de la sociedad considera que la violencia de género es algo natural, y que la mujer es culpable por el mal que padece. Por lo tanto, explicitar las diferentes formas de violencia, nombrarlas y tornarlas visibles proponiendo políticas públicas para el enfrentamiento de las mismas, también es una tarea para las (los) profesionales del Trabajo Social.

En un Artículo reciente, Lisboa (2010), se pondera que a lo largo de la historia de la profesión, el Trabajo Social permaneció distante de las luchas más significativas de los movimientos feministas, lo que configura un desencuentro y posible desconocimiento por parte de los estudiantes y profesionales sobre los estudios feministas y las cuestiones de género. Un gran número de Trabajadores Sociales todavía tienen dificultad para identificarse con el feminismo en función de una concepción negativa atribuida 
al concepto, o sea, una serie de estereotipos relacionados a una época en que "feminismo" parecía ser sinónimo de "un grupo de mujeres mal amadas, rebeldes y separatistas", consecuentemente, mal vistas por la sociedad en general (Lisboa, 2015).

En este sentido, se considera que las reflexiones académicas a partir de la perspectiva de género han contribuido para que pueda repensarse como han sido tratadas tradicionalmente, en los programas de los cursos de Trabajo Social, las nociones de: experiencia (Bach, 2010) epistemología feminista (Harding, 1996) y (Haraway, 1995), "descolonialidad" del saber (Lugones 2008 y 2014), ciudadanía y solidaridad política entre mujeres (Kubissa, 1994), equidad de género y empoderamiento femenino (Casique, 2007), entre otras. El debate en torno de estas categorías ha crecido en los últimos años, como puede percibirse a partir de las publicaciones recientes del área.

Pensar las cuestiones raciales, sociales y étnicas, juntamente con las categorías de clase y de género se tornó un eje fundamental para las defensoras del feminismo latinoamericano como Femenías (2007) y Miñoso (2010), que sugieren una relectura (una traducción) de las teorías eurocentricas "resignificándolas" para las problemáticas específicas de este continente. La realidad brasilera y latinoamericana es "singular", fundada en tres raíces poblacionales: la autóctona indígena; la europea blanca y la negra. Esa situación peculiar requiere "traer a colación nuestra historia de desplazamientos, reacomodaciones, resistencias, identidades mestizas" (Femenías, 2007, p.16), requiere una política de identidad, una abertura para la diversidad étnica y cultural; intersección entre las categorías género, clase, raza/etnia.

Se vislumbra, actualmente, un Trabajo Social cada vez más introducido en las luchas por el enfrentamiento a todas las formas de explotación, discriminación y prejuicio, resaltando un debate sobre la formación profesional capaz de acompañar los cambios sociales e históricos. De esta forma, se sugiere que la formación profesional de las/los trabajadores sociales pueda incluir la apropiación de una metodología que articule la dimensión teórica y la práctica construida a partir de la interseccionalidad, o sea, del entendimiento de que las categorías clase, raza/etnia, sexo, género, generación, 
nacionalidad, discapacidad, y otras que actúan de modo imbricado, estructuran las relaciones sociales marcadas históricamente.

Al introducir el concepto de interseccionalidad, Crenshaw (2002) se refiere a una asociación entre sistemas múltiples de subordinación, o sea, situaciones que ocurren entre dos o más ejes de la subordinación. La autora utiliza una metáfora de intersección, realizando una analogía con un cruzamiento de avenidas en que los varios ejes de poder, esto es, raza, etnia, género y clase constituyen las calles que estructuran los terrenos sociales, económicos y políticos. "Esas vías son a veces definidas como ejes de poder distintos y mutuamente excluyentes; el racismo, por ejemplo, es distinto del patriarcado, que a su vez es diferente de la opresión de clase" (Crenshaw, 2002, p.177). La autora nos advierte que tales sistemas, frecuentemente, se superponen y se cruzan, creando intersecciones complejas en las cuales dos, tres o cuatro ejes se entrecruzan. Por ejemplo, las mujeres negras o indígenas estarían más sujetas a ser afectadas por el intenso flujo de tránsito de todas esas vías, dado que comúnmente están posicionadas en un espacio donde el racismo o la xenofobia, la clase y el género se encuentran.

Se reconoce que el Trabajo Social tiene mucho para contribuir al conocimiento volcado a la elaboración, gestión y operacionalización de las políticas públicas con compromiso de promover la equidad de género. E1 cotidiano de la intervención profesional posibilita conocer la realidad polifacética de las mujeres en sus diferentes contextos, principalmente las que se encuentran en situación de violencia, tener acceso a datos que podrán contribuir para la construcción del aporte teórico del área, que por su parte puede subvencionar las políticas públicas con perspectiva de género.

\section{Violencia de género: una cuestión de poder y de dominación}

Se parte del supuesto de que la violencia es inseparable de la noción de género porque se basa y se ejerce en, y por la diferencia social entre mujeres y hombres. Incluir la noción de género en una definición de violencia es imprescindible, pues para Amorós (1995) el género constituye la construcción misma de la jerarquización patriarcal. La desigualdad entre hombres y mujeres es la clave de la discriminación sexista y el origen de toda la violencia de género. 
Para Velázquez (2006), "la palabra violencia indica una manera de proceder que ofende y perjudica a alguien mediante el uso exclusivo de la fuerza. Deriva de vis, fuerza" (p. 27). Sin embargo, no se pueden omitir otras formas de violencia que se ejercen por "imposición social", o por presión psicológica, cuyos efectos, como ya fue mencionado, producen tanto o más daño que la fuerza física. Estas diferentes formas de violencia son explicitadas a partir de los estudios de género que permiten identificarlas $\mathrm{y}$ vincularlas con pautas culturales y sociales diferenciadas para hombres y mujeres.

Coincidiendo con los significados de fuerza y coerción, para Heise (como se citó en Elías, 2009) la violencia contra las mujeres es considerada como "todo acto de fuerza física o verbal, coerción o privación amenazadora para la vida, dirigida a las mujeres o niñas, que cause daño físico o psicológico, humillación o privación arbitraria de libertad y que perpetúe la subordinación femenina” (p. 14). Esta definición explica algunos puntos centrales, de acuerdo con Elías (2009), para comprender la violencia identificada en un análisis empírico: a) especifica el sujeto a quien se dirige la violencia (mujer o niña); b) las características de la acción (coerción o privación); c) el tipo del daño que puede resultar de la acción (psicológica, física, económica o sexual); d) la pretensión del acto (perpetuar la subordinación de las mujeres).

La violencia contra las mujeres ocurre en un contexto socio histórico de una sociedad patriarcal jerárquica, de múltiples opresiones, lo que es confirmado por Ferrer (2011):

En las relaciones de poder existentes en el interior de las familias y particularmente en las relaciones de intimidad, la violencia se convierte en una herramienta de poder y control social para mantener y perpetuar los intereses de los hombres frente a los de las mujeres (p. 65).

Según esta perspectiva, la violencia contra las mujeres ocurre predominantemente en el espacio doméstico y es perpetrada principalmente por hombres. Sin embargo, es importante mencionar que la "violencia doméstica" no excluye a las mujeres como agentes contra otras mujeres y niñas con menor poder de jerarquía dentro del espacio temporal doméstico. Eso 
significa que la "protagonista" de la violencia, eventualmente puede ser una mujer joven contra una mujer anciana, la hermana mayor contra las más joven, violencia entre parejas homoafectivas o las suegras que maltratan a las nueras (y viceversa) entre otros ejemplos.

Integrando las perspectivas presentadas enunciadas hasta el momento, se amplía la definición de violencia de género con base a lo dicho por Velázquez (2006), para la cual: violencia de género abarca todos los actos mediante los cuales se discrimina, se ignora, se somete o se subordina a las mujeres en los diferentes momentos de su existencia.

Debe resaltarse que los estudios de género han contribuido para descifrar el inquietante cuestionamiento: ¿por qué a lo largo de la historia, la diferencia sexual ha sido el fundamento de la subordinación femenina, consecuentemente, el fundamento de la desigualdad social?

Para Scott (1995), la categoría género se utiliza para designar las relaciones sociales entre los sexos. La autora afirma que no existe un mundo de las mujeres separado de un mundo de los hombres. "La información sobre las mujeres es necesariamente información sobre los hombres, un estudio implica el otro. (...) Este uso rechaza la utilidad interpretativa de esferas separadas" (p.80).

Lo central de su definición del género es la "conexión” entre dos ideas: "el género es un elemento constitutivo de las relaciones sociales basadas en las diferencias que distinguen los sexos y el género es una forma primaria de relaciones de poder" (Scott, 1995, p.86).

Para la autora, el género es el campo primario dentro del cual y por medio del cual se articula el poder, y resalta que el proceso histórico social también está compuesto por procesos políticos, que asumen diferentes significados conforme los sujetos y las instituciones sociales les van atribuyendo; luego, los estudios sobre las relaciones de género lanzaron nuevas miradas sobre viejas cuestiones, haciendo emerger una "nueva historia", redefiniendo y reestructurando las relaciones entre hombres y mujeres, sujetos múltiples que requieren concepciones de análisis plurales, o sea, de clase, raza/etnia, y de género (Scott, 1995). 
Al analizar la dominación masculina, Bourdieu (2003) argumenta que la lógica de género es una lógica de poder y de dominación, es la forma paradigmática de la "violencia simbólica", o sea, aquella violencia ejercida sobre un agente social con su complicidad y su consentimiento. Para el autor, la cultura marca a los seres humanos con el género y el género marca a la percepción de lo social, de lo político, de lo religioso, de lo cotidiano. La lógica del género también funciona como una Institución inscripta por milenios en la objetividad de las estructuras sociales y en la subjetividad de las estructuras mentales. Dice el autor, que el orden social masculino está tan profundamente arraigado que no requiere justificación: se impone a sí mismo como autoevidente, y es tomado como "natural", gracias al acuerdo casi perfecto e inmediato que obtiene por un lado de las estructuras sociales y por otro de las estructuras cognitivas inscritas en los cuerpos y en las mentes.

Por otro lado, siendo la violencia de género una forma de afirmar el poder y el control de los hombres sobre las mujeres, Foucault (1985) advierte que donde hay poder hay resistencia, lo que remite al apelo a las mujeres sobrevivientes de la violencia para producir formas alternativas de poder y resistencia actuando como "sujetos libres", dado que el autor diferencia relaciones de poder y de dominación. En esta última, la capacidad de actuar deja de existir por tratarse de una relación fija y asimétrica; mientas que en las relaciones de poder las acciones se vuelven para el otro reconocido como sujeto. Por lo tanto, para el autor: “(...) ahí donde hay poder, hay resistencia (...) las relaciones de poder no pueden existir sino en función de una multiplicidad de puntos de resistencia; ellas (las resistencias) son el otro lado de las relaciones de poder" [transcripción de la autora] (Foucault, 1988, p. 91).

Esta correlación de fuerzas (entre poder y formas de resistencia) está presente, conforme Segato (2003), en todo el contexto sociocultural incluyendo las Instituciones jerárquicas y patriarcales, las normas culturales sexistas y racistas, la forma como fuimos socializados, con base en una perspectiva de género que aprueba y legitima la violencia contra las mujeres aliada a la interseccionalidad de las múltiples formas de opresión que las mujeres sufren en la sociedad, por las cuestiones de género, clase y raza/ etnia. 
En este sentido, los estudios feministas han sugerido estrategias de intervención contra la violencia doméstica que van desde promover cambios en las normas sociales y culturales a través de la educación, la creación de grupos de concientización, apoyo y empoderamiento tanto para hombres(autores o no de violencia) como para mujeres (en situación o no de violencia); campañas a través de los medios de comunicación, reformulación de la legislación, hasta la creación de programas de capacitación para técnicos que trabajan con la problemática de la violencia .

Para deconstruir esa estructura simbólica de poder y dominación, los estudios feministas invitan a adoptar una "perspectiva de género" en las formas de pensar y actuar, en los procesos de intervención profesional, partiendo de una concepción crítica de la "visión androcéntrica" de la humanidad, que acabó por excluir a la mitad del género humano de los espacios sociopolíticos. La perspectiva de género propone lanzar una nueva mirada sobre la realidad a partir de las mujeres y con las mujeres revolucionando el orden de los poderes.

La creciente incorporación de la perspectiva de género en la elaboración de políticas públicas, interpretaciones y diagnósticos ha permitido, según Lagarde (1996), la visibilidad de las mujeres y de la problemática que las involucra, así como ha contribuido para los avances en la emancipación femenina. Teniendo en cuenta la actual situación de desigualdad en que se encuentran las mujeres, consideradas ciudadanas y sujetos de derecho, se reclama el papel del Estado en el enfrentamiento de ese asunto.

\section{El enfrentamiento de la violencia contra las mujeres como deber y responsabilidad del Estado}

La Convención Interamericana para Prevenir, Punir y Erradicar la Violencia contra la Mujer, más conocida como "Convención de Belém do Pará"16, ratificada por Brasil en 27 de noviembre de 1995, destaca el derecho de toda mujer a una vida libre de violencia, que comprende el derecho a ser libre de todas las formas de discriminación y de ser valorizada y educada

${ }^{16}$ La "Convenção de Belém do Pará" se encuentra disponible en el site de la Comisión Interamericana de Derechos Humanos: http://www.cidh.oas.org/basicos/portugues/m. Belem.do.Para.htm 
padrones libre de estereotipados de comportamiento y costumbres sociales y culturales basados en conceptos que la coloquen en un lugar de inferioridad o subordinación (Convenção de Belém do Pará, 1995).

En el Capítulo III, la Convención introduce los deberes que deben ser asumidos por los Estados, debiendo ser tenida en cuenta la situación de la mujer vulnerable a la violencia por su raza, origen étnico o condición de migrante, de refugiada o de desplazada. Se destacan entre algunos deberes del Estado que el mismo debe actuar con el debido celo para prevenir, investigar y penalizar la violencia contra la mujer; y prestar servicios especializados apropiados a la mujer sujeta a la violencia, por intermedio de entidades de los sectores público y privado, inclusive refugios, servicios de orientación familiar, cuando fuera el caso (Organização dos Estados Americanos, 1995).

En 2003, fue creada en Brasil, la Secretaria Especial de Políticas Públicas para Mujeres (SPM), en la época, con status de Ministerio, constituyéndose en un marco en la historia de la lucha de las mujeres brasileras en la medida en que trazó como meta incorporar la igualdad de género como un tema transversal en las políticas públicas. A partir de esta instancia nacional, fueron creados en la esfera de los Estados y Municipios, los Consejos de Derechos de las Mujeres y las Coordinadoras Especiales de Mujeres, responsables por la elaboración y articulación de las políticas para mujeres, garantizando y fiscalizando programas, proyectos que modifican las condiciones de vida de las mujeres, ofreciendo oportunidades de empoderamiento y contribuyendo a la equidad de género.

Un marco histórico en la vida de las mujeres fue la IV Conferencia Mundial de las Mujeres en Beijing de 1995, que señaló como estrategia la defensa junto a los Estados de la "gendermainstreaming", conocida como transversalidad de género en las políticas públicas, que preconiza la incorporación de la mejoría de status de las mujeres en todas las dimensiones de la sociedad- económica, política, cultural y social (Organización de las Naciones Unidas, 1995).

Fruto de amplio debate a nivel nacional que involucró millares de mujeres en Brasil, y resultado de un proceso participativo que ocurrió 
a través de la realización de Conferencias (municipales y estaduales), el "Plano Nacional de Políticas para las Mulheres" (2004), en su capítulo $\mathrm{IV}$, que trata sobre el enfrentamiento de la violencia cometida contra las mujeres, resalta que:

Cabe al Estado adoptar una política sistemática y continuada en diferentes áreas. La intervención debe caracterizarse por la promoción e implementación de políticas públicas de responsabilidad de los gobiernos federal, estaduales y municipales, constituyendo una red de acciones y servicios. Las redes deben articular asistencia jurídica, social, servicios de salud, seguridad, educación y trabajo. Los servicios y organizaciones que componen las redes incluyen: Estaciones de Policía Especializadas en la Atención a la Mujer, Estaciones de Policía comunes, Centro de Referencia, Defensorías Públicas de la Mujer, Defensorías Públicas, Instituto Médico Legal, Servicios de Salud, Policía Militar, Cuerpo de Bomberos, Casas Refugios (p. 75).

La Ley No 11.340, conocida popularmente como "Ley Maria da Penha", fue aprobada en Brasil en agosto de 2006 con el principal objetivo de representar un instrumento jurídico eficaz que contenga las disposiciones legales y mecanismos para cohibir y prevenir la violencia doméstica y familiar contra las mujeres. Conforme Santos (2010) y Pasinato (2015), la referida Ley, también trae aspectos conceptuales y educativos, dado que se propone promover un cambio real en los valores sociales de la sociedad brasilera, que banaliza la violencia que ocurre en las relaciones domésticas y familiares, y legitima los padrones de supremacía masculina y subordinación femenina, aceptados por la humanidad durante siglos.

Las principales innovaciones aportadas por la Ley No 11.340 (2006) son: a) tipifica y define la violencia doméstica y familiar contra la mujer como un crimen; b) establece las formas de violencia doméstica contra la mujer como física, psicológica, sexual, patrimonial y moral; c) determina que la violencia doméstica contra la mujer es independiente de su orientación sexual; d) crea Juzgados Especiales de Violencia Doméstica y Familiar contra la Mujer, con competencia civil y criminal para todas las cuestiones; e) prevé un capítulo específico para el atendimiento, por autoridad policial, para los casos de violencia doméstica contra la mujer; f) define que la mujer 
solamente podrá renunciar al proceso ante un juez; g) veda la entrega de la intimación al agresor por la mujer; h) posibilita la prisión en flagrante; i) altera el Código de Proceso Penal para posibilitar al juez decretar la prisión preventiva, cuando haya riesgos para la integridad física o psicológica de la mujer; j) determina que la mujer víctima de violencia doméstica será notificada de los actos procesales, especialmente los relacionados al ingreso y salida de prisión del agresor; 1) determina que la mujer deberá estar acompañada de un abogado defensor en todos los actos procesales.

La efectividad e implementación de la Ley Maria da Penha, sin embargo, requiere por parte de los agentes públicos el entendimiento de los supuestos analíticos (transversalidad de género) que subyacen a esta cuestión bien como la garantía de la gobernabilidad, en tres dimensiones articuladas: a) voluntad y decisión política que contemple, junto a los planificadores, la garantía de que el Estado (Municipio) desarrolle políticas que incidan efectivamente sobre la desigualdad estructural entre hombres y mujeres; b) incorporación de la perspectiva de género junto a la práctica de los gestores, que ejecutan, monitorean y evalúan las políticas públicas en los niveles federal, estadual y municipal; c) diseminación de nuevos valores culturales y políticos junto a la población, con vistas a una ciudadanía inclusiva.

En este sentido, proponemos como estrategia que los profesionales que actúan en el área de la violencia contra la mujer, a partir de las demandas percibidas en el atendimiento cotidiano, puedan trabajar de forma más articulada y proponer políticas públicas eficaces, definir el presupuesto en el "Plano Pluri Anual" garantizando recursos materiales, humanos y financieros; presionar a los gestores para que den prioridad a la problemática, solidificar y divulgar la red de atendimiento en el enfrentamiento de esta problemática, trabajando en la perspectiva de la interdisciplinaridad.

\section{E1 Trabajo Social integrando el equipo interdisciplinar en el atendimiento a las mujeres en situación de violencia}

Toda mujer en situación de violencia que procura atendimiento especializado, sea en una Estación de Policía de las Mujeres, en un Centro de Referencia, junto al Juzgado Especial de la Violencia, Defensoría Pública, Atendimiento Socio Jurídico junto a las Universidades, Hospitales o Pues- 
tos de Salud, entre otros, espera ser atendida por un equipo de técnicos preparados, o sea, capacitados y con sensibilidad para actuar en el área de la violencia.

La mayoría de las mujeres en situación de violencia llega a los servicios que brindan asistencia con mucha vergüenza y gran dificultad para hablar sobre su padecimiento. En este contexto es necesario que la situación que las mujeres traen al atendimiento sea acogida y tratada con respeto y sigilo profesional. En general, las mujeres en situación de violencia llegan a la consulta con la subjetividad arrasada; cuando se dice: "esta mujer fue violentada”, significa que fue agredida en su más íntima identidad, en aquello que las constituye como personas humanas. Las Trabajadoras Sociales (o Psicólogas) son las profesionales que realizan el primer abordaje, reciben a las mujeres, y a través de una "escucha social calificada" realizan una entrevista, generalmente, para saber la demanda y completar el registro socioeconómico de la usuaria. Este espacio de escucha es fundamental para que la mujer en situación de violencia pueda romper el silencio impuesto. Es el momento en que ella se sentirá segura frente a una profesional que transmite confianza, que cree en lo que ella va a decir, que la respeta y la alienta a expresar sentimientos que hasta ese entonces estaban guardados por miedo o confusión, y que ahora ella misma es capaz de ordenar y aclarar.

Este es el momento en que las profesionales podrán proponer estrategias de enfrentamiento y de resistencia para las mujeres en situación de violencia. Lagarde (1999) identifica cuatro formas de las mujeres para enfrentar la violencia: 1) asumiendo la naturalización de la dominación y de la opresión; 2) resistiendo y desobedeciendo al poder; 3) subvirtiendo el orden familiar, conyugal, laboral y de todo tipo con acciones opuestas y contrarias; 4) transgrediendo, que es la síntesis de las tres formas anteriores mediante el estabelecimiento de un orden propio, no definido por las normas tradicionales.

Frente a estos tipos de enfrentamiento, la/el profesional del Trabajo Social podrá elaborar junto con la mujer en situación de violencia, un plan individual y/o familiar de atendimiento. Para ello, deberán ser establecidas articulaciones entre las Redes de Servicios para que esa mujer (y probablemente sus hijos) pueda ser atendida de acuerdo con los Programas y 
Proyectos definidos en la Política de Asistencia Social; acompañar el desarrollo de las situaciones de cada usuaria, articulando con las diferentes unidades de los Centros de Referencia de Asistencia Social (Especializados o no), de cada región o barrio, u otras instancias con las cuales puedan establecer intercambio de informaciones, como por ejemplo, transferencia de jardín de infantes o de escuela de las/os niñas/os mientras que la mujer se encuentra "refugiada" (Casa Abrigo). Siempre que sea necesario, será realizada una visita domiciliaria, pues esta se configura como un instrumento significativo para conocer la realidad en la cual vive la mujer, principalmente en procesos que demandan el trabajo con la familia, o cuando involucra la guarda de las/os niñas/os, exigiendo un mejor acompañamiento de la situación con un estudio socio-familiar.

Orientaciones básicas sobre sus derechos podrán ser brindadas por la/el profesional del Trabajo Social, bien como en relación a los diferentes tipos de violencia y sus respectivas penas; la importancia de realizar la denuncia; los mecanismos de protección previstos en la Ley Maria da Penha, esclareciendo las opciones de derivación para las diferentes Instituciones de la Red Socio-Asistencial. Instrumentales Técnico Operativos como "Talleres con Mujeres en situación de violencia” podrán ser utilizados, bien como trabajos con grupos junto a los Centros de Referencia en Asistencia Social (CRAS); divulgación de informaciones sobre la cuestión de la violencia a través de Folletos y Volantes conteniendo: los lugares en los que se ofrece asistencia; explicación sobre los derechos de las mujeres y sobre los mecanismos de protección previstos en la Ley Maria da Penha; y orientación para prevenir las agresiones y humillaciones, entre otras.

Es importante que el equipo interdisciplinar elabore y proponga un "Protocolo de la Violencia", para que las situaciones de violencia contra la mujer sean tratadas de forma articulada por una Red de Servicios, permitiendo la "intersectorialidad" entre los servicios ofrecidos por las Instituciones que integran las políticas públicas municipales, entre ellas la salud, educación, trabajo, vivienda, asistencia social, entre otras. Son parte de esta red las Secretarias Municipales (Salud, Educación, Vivienda entre otras), los Consejos de Derechos, y todas las instituciones que tienen convenio con el municipio y que están vinculadas a la problemática de la violencia como: 
las Estaciones de Policía de las Mujeres, el Centro de Referencia en Atención a Mujeres en Situación de Violencia (CREMV), la Casa de Pasaje de acogida), las Casas de Protección o Abrigos para Mujeres en situación de violencia severa o con amenaza de muerte, el "Disque Denuncia", el Protocolo de Atención a las Víctimas de Violencia Sexual, los Hospitales, el Instituto Médico Legal, la atención socio-jurídico en las Universidades, las Defensorías Públicas, o "Balcão da Ciudadanía”, el Centro de Atención Psicológica (CAPS), el Centro de Rehabilitación y Tratamiento de Adictos (CRETA), el Instituto Nacional de Seguridad Social (INSS), y las demás redes vinculadas a las políticas públicas municipales. Una intervención en red puede ampliar la autonomía de los sujetos involucrados, extrapolando la acción individual de un profesional para con las usuarias y sus hijos. Un Beneficio Eventual de Asistencia Social (BEAS), podrá ser destinado a las mujeres que necesiten salir del espacio doméstico, en función de la violencia, y no tengan como sobrevivir por otros medios (Veiga, Lisboa y Wolff, 2016).

Reuniones con el equipo interdisciplinar: trabajadores sociales, psicólogos, abogados y eventualmente, médicos, enfermeros (del Instituto Médico Legal o de otra unidad de salud), policías que intervengan en las situaciones de violencia por las cuales las mujeres están pasando son decisivas para la derivación correcta de las situaciones. Es muy importante establecer una alianza de trabajo entre los integrantes del equipo que acompañan la misma situación con el objetivo de analizar el mismo caso, oír los diferentes pareceres o informes de sus colegas, socializar los datos (diagnóstico) para que las intervenciones puedan ser realizadas de la forma más correcta posible. La interdisciplinaridad fortalece los lazos de solidaridad, ejercita la convivencia y la cooperación, existe respecto a los diferentes saberes y permite la convergencia de estos en pro de un mismo objetivo que es la lucha por el fin de la violencia contra las mujeres.

\section{Consideraciones finales}

Se pretendió mostrar en este artículo, que los profesionales del Trabajo Social, tanto en Brasil como en América Latina están siendo requeridos, cada vez más, para actuar junto a instituciones que trabajan con la Violencia de Género. Para que la intervención de esos profesionales sea reconocida 
y valorada es necesario que el proceso de formación incluya conocimientos específicos relacionados a esa área, o sea, que las/los Trabajadoras Sociales puedan interesarse por los estudios feministas, cuestiones de género, étnico-raciales, construcción de la identidad y diversidad sexual, insistiendo en la importancia de la transversalidad de esas categorías en la mediación teórica sobre las demandas que surgen en el cotidiano de sus prácticas.

Cabe resaltar que en los últimos 30 años, el movimiento feminista en Brasil luchó para el reconocimiento de la "violencia de género" por la vía Judicial y los resultados alcanzados son parte de una importante estrategia política. La presión organizada por los movimientos feministas tuvo un papel fundamental en todo el proceso de elaboración de leyes y de las propuestas de políticas públicas que tenemos hasta el presente momento, para enfrentar y, sobretodo disminuir la violencia doméstica y familiar contra la mujer.

Trabajar con la temática de la violencia de género bien como con políticas públicas para mujeres requiere por parte de los profesionales, gestores, agentes públicos y juristas, la comprensión de los presupuestos analíticos que fundamentan esta problemática. Requiere la incorporación de una perspectiva cuya base sea la equidad de género, o sea, la elaboración de una nueva matriz (transversalidad de género) que oriente la visión de los poderes (político, institucional y administrativo), y un compromiso en asumir la responsabilidad en relación a la superación de las asimetrías de género entre las diferentes esferas de gobierno. Para eso, es necesario: a) destinar recursos para la implementación de la Ley Maria da Penha a través de la dotación de presupuesto en los Planos Plurianuales de los Gobiernos; b) brindar cursos de capacitación en derechos humanos y violencia de género para policías y funcionarios que trabajan con la problemática de la violencia; c) creación de Centros de Reeducación y Rehabilitación para hombres autores de violencia; d) garantizar contenidos que contemplen el enfoque de género y violencia de género en las escuelas y cursos universitarios de Trabajo Social, Psicología, Derecho entre otros.

Es importante crear programas para adolescentes y jóvenes, para que las nuevas generaciones puedan adoptar modelos relacionales basados en el respeto a los derechos de las personas, en las responsabilidades individuales 
y con respeto a las diferencias. La perspectiva de género exige una nueva postura sobre la visión del mundo, sobre los valores, y sobre el modo de vida, o sea, coloca en crisis la legitimidad del mundo patriarcal. Esa perspectiva permite comprender que las relaciones de desigualdad e inequidad entre géneros son un producto del orden social dominante y de las múltiples opresiones de clase, raza, etnia y generación que se ejercen sobre las mujeres y configuran una superposición de la dominación.

Se reconoce que la incorporación del debate sobre la equidad de género en las políticas públicas en Brasil es resultado de un largo proceso social y político de participación, sustentado en gran medida por la visibilidad y legitimidad que el movimiento de mujeres ha alcanzado en los últimos treinta años, por el tipo y por la calidad de la producción de conocimiento sobre la temática de las relaciones de género, y por la resistencia de las $\mathrm{mu}-$ jeres en el escenario político y social como sujetos sociales.

¡Quedan invitados los profesionales del Trabajo Social a comprometerse en las luchas feministas y que en conformidad con nuestro Proyecto Ético Político, se pueda contribuir para que las mujeres puedan tener una vida libre de violencia! 


\section{Referencias bibliográficas}

Amorós, C. (1995).Diez palabras clave sobre Mujer. España: Navarra.

Bach, A. M. (2010). Las voces de la experiencia. El viraje de la filosofía feminista. Buenos Aires: Editorial Biblos.

Bourdieu, P. (2003). A dominação masculina. Rio de Janeiro: Bertrand.

Casique, I. (2007). El complejo vínculo entre empoderamiento de la mujer y violencia de género. En Castro, R.; y Casique, I. (Eds.), Estudios sobre cultura, género y violencia contra las mujeres (p.231-259). Cuernavaca, UNAM, Centro Regional de Investigaciones Multidisciplinarias.

Crenshaw, K. (2002) Documento para o Encontro de Especialistas em Aspectos da Discriminação Racial Relativos ao Gênero.Revista Estudos Feministas, 10(01), 171-188.

Femenías, M. L. (2007). Esbozo de un feminismo latinoamericano. Revista Estudos Feministas, 15(1), 11-25.

Ferrer, D. V. (2011) Espacios de libertad: mujeres, violencia doméstica y resistencia. Buenos Aires, Espacio Editorial.

Foucault, M. (1985). História da Sexualidade Vol. I: A vontade de saber. 5a. Edição Rio de Janeiro: Graal.

Haraway, D. (1995). Saberes localizados: a questão da ciência para o feminismo e o privilégio da perspectiva parcial. Cadernos pagu, (5), 7-41.

Harding, S. (1996). Del problema de la mujer en la ciencia al problema de la ciencia Sexualidad y salud reproductiva: avances y retos para la investigación. (p. 235-273) México: Colegio de México en el feminismo. Ciencia y Feminismo. Madrid: Ediciones Morata, 15-27.

Elías, M. G. H. (2009). ¿Violencia de género o violencia falocéntrica?: variaciones sobre un sistema complejo (Vol. 546). México, Instituto Nacional de Antropología e Historia. 
Kubissa, L. P. (1994). Pactos entre Mujeres. En AMORÓS, C. (Ed.), 10 palabras clave sobre mujer (p. 331-365). Estella (Navarra), España: Editorial Verbo Divino.

Lagarde, M. (1996). Género y feminismo. Desarrollo humano y democracia. Colección Cuadernos Inacabados, (25).

Lagarde, M. (1999). Una mirada feminista en el umbral del milenio (No. 305.4 L3).

Ley No 11.340. Ley Maria da Penha. Diário Oficial da União. Brasília, 7 de agosto de 2006. Recuperado de http://www.planalto.gov.br/ ccivil_03/_ato2004-2006/2006/lei/111340.htm

Lisboa, T. K. (2010). Gênero, feminismo e Serviço social: encontros e desencontros ao longo da história da profissão. Revista Katálysis, 13(1), 66-75. Recuperado de http://www.scielo.br/scielo.php?script=sci_Arttextypid=S1414-49802010000100008ylng=ptynrm=iso

Lisboa, T. K.; y de Oliveira, C. N. (2015). Serviço Social com Perspectiva de Gênero: o que a "cegueira ideológica" não permite ver. Revista Feminismos, 3(2/3). Recuperado de http://www.feminismos.neim.ufba. br/index.php/revista/Article/view/312

Lugones, M. (2014). Rumo a um feminismo descolonial. Estudos Feministas, 22(3), 935-952.

Lugones, M. (2008). Colonialidad y Género. Tabula Rasa, (9), 73-102. Recuperado de http://www.scielo.org.co/scielo.php?script=sci_Arttextypid=S1794-24892008000200006ylng=enytlng=es.

Miñoso, Y. E. (Ed.). (2010). Aproximaciones criticas a las prácticas teóricopoliticas del feminismo latinoamericano. Buenos Aires: En la Frontera.

Organização dos Estados Americanos (1995). Convenção Interamericana para Prevenir, Punir e Erradicar a Violência Contra a Mulher. Belém/PA (Brasil): Comissão Interamericana de Direitos Humanos. Recuperado de http://www.oas.org/juridico/spanish/tratados/a-61.html 
Organización de las Naciones Unidas (1995). IV Conferencia Mundial sobre la Mujer Recuperado de http://www.un.org/womenwatch/daw/ beijing/pdf/BDPfA\%20S.pdf

Pasinato, W. (2015) Oito anos de Lei Maria da Penha: Entre avanços, obstáculos e desafios. Revista Estudos Feministas. 23 (2), 533-545.

Santos, C. M. (2010) Da delegacia da mulher à Lei Maria da Penha: Absorção/tradução das demandas feministas pelo Estado. Revista Crítica de Ciências Sociais (89), 153-170.

Scott, J. (1995). Gênero: uma categoria útil de análise histórica. En: Revista Educação y Realidade. Faculdade de Educação-UFRGS. 20(2).

Secretaria Especial de Políticas para as Mulheres de Brasil. (2008). Proposta para Implementação dos Serviços de Responsabilização e Educação dos Agressores.

Secretaria de Políticas para as Mulheres de Brasil (2004). Plano Nacional de Politicas para as Mulheres. Brasília. http://www.spm.gov.br/assuntos/ pnpm/plano-nacional-politicas-mulheres.pdf

Segato, R. L. (2003) Las Estructuras Elementales de la Violencia. Buenos Aires: Prometeo.

Veiga, A. M.; Lisboa, T. K; y Wolff, C. S. (2016). Gênero e violências: diálogos interdisciplinares. Florianópolis: Edições do Bosque/CFH/UFSC.

Velázquez, S. (2006). Violencias cotidianas, violencia de género. Escuchar, comprender, ayudar. Buenos Aires, Argentina: Paidós. 